\title{
NÍVEL DE MATURIDADE DE ARRANJOS PRODUTIVOS LOCAIS (APL): UM DIAGNÓSTICO NO APL DE BONÉS DE APUCARANA - PR
}

\section{MATURITY LEVEL OF LOCAL PRODUCTIVE ARRANGEMENTS (LPA): A DIAGNOSIS OF THE CAPS LPA IN APUCARANA - PR}

\author{
Rodolfo Reinaldo Petter* E-mail: rodolfopetter@gmail.com \\ Luis Mauricio Resende* E-mail: Imresende@utfpr.edu.br \\ Fabrício Alexandre Alves Ceranto*E-mail: fabricioceranto@hotmail.com \\ *Universidade Tecnológica Federal do Paraná - UTFPR, Ponta Grossa, PR
}

\begin{abstract}
Resumo: $O$ presente trabalho teve como objetivo de avaliar o nível de maturidade do arranjo produtivo local de bonés de Apucarana - PR, de modo que seja possível identificar os aspectos que envolvem a cadeia produtiva que necessitam de melhorias. Para alcançar este objetivo, aplicou-se para a governança do aglomerado, o questionário desenvolvido por Pietrobon (2009), no qual, o nível de maturidade é determinado a partir da avaliação de 14 aspectos relacionados com a cadeia produtiva de um APL e que, consequentemente, interferem na competitividade das empresas da rede. Assim, esta pesquisa classifica-se como aplicada do ponto de vista de sua natureza, visando gerar conhecimentos para aplicação prática no aglomerado pesquisado, também úteis na resolução de problemas específicos, tanto no âmbito empresarial como no científico, onde pouco se tem abordado a gestão de aglomerados sob o ponto de vista do nível de maturidade. Quanto à forma de abordagem, a pesquisa classifica-se como quali-quantitativa, pois mapeia o nível de maturidade de forma quantitativa, ao mesmo tempo em que fornece resultados qualitativos úteis para direcionar o gerenciamento do aglomerado. Como resultado, foi possível obter informações que terão utilidade na realização de melhorias por parte da governança do APL. O escore obtido foi considerado positivo, porém aponta um abrangente leque de melhorias que podem ser realizadas na rede por parte da governança objetivando o aumento da competitividade das empresas da rede e consequente aquecimento da economia local/regional.
\end{abstract}

Palavras-chave: Maturidade. Arranjo Produtivo Local. Competitividade. Rede de Empresas. APL.

\begin{abstract}
The aim of this study was to evaluate the maturity level of a Caps cluster, capable to analyze the points on which the cluster is the need to make improvements. This research is classified as an applied research, aimed at generating knowledge for practical application in the crowded universe of research, also useful in solving specific problems, in this case the approach is little in the literature of maturity in production clusters, in contrast to the importance this practice in the management of productive agglomerations. This research also ranks on his way to as qualitative and quantitative approach. Data collection took place through the application of a questionnaire developed by Pietrobon (2009), at a Caps Cluster located in Apucarana - Brazil. This search tool maps the maturity of productive clusters through 14 qualitative dimensions, where each has subdivisions that are deployed on specific issues. They still have a numerical weight assigned to you which subsequently generate a score for assessing the maturity level of APL. As results were known information that will be useful as a basis for necessary improvements to the management of APL, which must be shaped according to the specifics of the arrangement, but that foster progress toward this. The score was considered positive, but this points to a broad range of necessary improvements to the maturity level of agglomeration studied.
\end{abstract}

Keywords: Maturity. Local Productive Arrangement. Development of productive clusters. Competitiveness. 


\section{INTRODUÇÃO}

No decorrer dos últimos anos a busca pelo aumento da competitividade fez com que empresas de um mesmo setor fizessem uma ligação conjunta e coordenada, objetivando tornarem-se mais fortes em relação às instabilidades do mercado. Esses conjuntos de empresas são chamados aglomerados produtivos, constituídos na sua maior parte por micro e pequenas empresas, onde a cooperação interfirmas é a base da busca pelo desenvolvimento estrutural e competitivo.

Esta cooperação gera uma maior capacidade produtiva e de inovação, resultando no desenvolvimento apurado de capacidades para o embate da competição externa. Alter e Hage (1993) comentam que elas atuam em um mesmo espaço geográfico, com identidade cultural e vínculo, que favorece a troca de informações e envolve uma correlação em diversos setores, devido à grande relação social. Além da proximidade física e da forte relação com os agentes da localidade, os arranjos produtivos locais têm em comum a mesma dinâmica econômica.

As micro e pequenas empresas são as maiores contribuintes atuando em uma atividade produtiva principal, onde por meio da cooperação, contribuem significativamente na geração de empregos, melhorando a distribuição de renda e, por extensão, contribuindo economicamente para a região onde estão localizadas.

Essa união entre as empresas do mesmo setor fomenta o desenvolvimento de vantagens competitivas como a capacidade de gerar economias de escala, de investir em inovação produtiva e gerencial, inserir firmas de pequeno porte no mercado externo para que possam competir com empresas de maior poder econômico e contribuir para o aumento da qualidade dos produtos.

Há também a relação com a presença de setores correlatos de apoio, os quais se tornam um fator determinante para a vantagem competitiva. Por meio do intercâmbio técnico e do fluxo de informações, gera-se um aceleramento no ritmo da melhoria e inovação, além de expandir as chances do desenvolvimento de habilidades nas empresas, constituindo-se dessa forma uma fonte de entrantes que constituirá uma abordagem renovada para competição (PORTER, 1999b).

Essa nova abordagem se foca na eficiência coletiva, da qual aperfeiçoa essa gama de variáveis. Atividade esta, que se faz possível e visível apenas por meio do desenvolvimento ao longo do tempo, apoiado pela execução de um trabalho específico e cauteloso de monitoramento e diagnóstico em torno da melhoria 
contínua desse molde de gestão.

Desta forma, para organizar esse construto de atividades voltadas ao desenvolvimento, constitui-se uma governança no aglomerado. Esta delineia as ações a serem tomadas para atingir um maior nível de maturidade de tal sistema produtivo.

Frente a isso, julga-se de significativa importância o diagnóstico e avaliação do nível de maturidade dessas aglomerações, tarefa que pode ser realizada pela governança do aglomerado por meio dos instrumentos disponíveis na literatura, como a ferramenta desenvolvida por Pietrobon (2009), donde foi utilizada nesta pesquisa para o diagnóstico e avaliação do APL de Bonés de Apucarana.

\section{ARRANJO PRODUTIVO LOCAL - APL}

O termo Arranjo Produtivo Local - APL têm sido conceituados com diferentes enfoques de acordo com cada autor, porém não se contradizem e sim se complementam. A origem do termo deu-se por meio do surgimento de distritos industriais italianos da originária Terceira Itália. São casos de Arranjos Produtivos Locais aqueles que as empresas participantes ainda não se encontram tão fortemente ligados e articulados (REDESIST, 2005).

Cassiolato e Lastres (2003) e Garnica e Contreras (2007), explicam de forma ampla que os APLs podem ser caracterizados como aglomerações territoriais/geográfica de agentes econômicos, políticos e sociais, com foco em um conjunto específico de atividades econômicas, atuando em uma mesma atividade e/ou segmento. Assim, os atores presentes nestas aglomerações apresentam vínculos mesmo que incipientes.

Este molde de atuação industrial geralmente envolve a participação e a interação de empresas que podem ser desde produtoras de bens e serviços finais até fornecedoras de insumos e equipamentos, ou ainda prestadoras de consultoria e serviços, comercializadoras, clientes, institutos de pesquisa e desenvolvimento (P\&D), órgãos governamentais. Instituições voltadas para formação/capacitação dos recursos humanos envolvidos no sistema completam os autores.

Para Porter (1999a) o conceito de aglomerado possui uma representação de um novo pensamento às economias, indicando novos painéis para governos, 
instituições e empresas que possuem o objetivo comum de aumentar a competitividade local. Além da identificação dos membros participantes do APL como empresas semelhantes, instituições de ensino e qualificação profissional e distribuidores de insumos, a análise da cadeia verticalizada e posicionada subseqüente à horizontal, estrutura um fator de importância na busca de agencias governamentais e outros órgãos reguladores que exerçam influencias significativas sobre os participantes dos aglomerados.

A integração funcional e a estruturação de redes têm gerado vantagens relevantes às organizações na busca pela rapidez para o processo inovativo. Para Lastres e Cassiolato (2003) a flexibilidade, fertilização de idéias e interdisciplinaridade de idéias ao patamar administrativo e laboratorial tem grande relevância nos elementos que configuram o sucesso competitivo das organizações.

Albagli e Brito (2003) enumeram três possíveis formas de cooperação nos arranjos produtivos locais: a troca de informações produtivas, mercadológicas e tecnológicas, seja com clientes, concorrentes ou fornecedores; a interação entre empresas e outras instituições, por meio de programas de treinamento, compras conjuntas de insumos ou promoção de eventos em geral e; a integração de competências entre as próprias empresas e entre empresas e outras instituições, por meio de ações de melhoria de produtos e processos e também atividades de pesquisa e desenvolvimento.

\section{MATURIDADE EM AGLOMERADOS PRODUTIVOS}

Pietrobon (2009) enfatiza a relevância da maturidade nas organizações, sobretudo nos aglomerados produtivos:

\footnotetext{
A questão da maturidade corporativa é uma preocupação natural das empresas. A maturidade pode identificar qual o estágio ou nível que a empresa encontra-se e a partir disso, permitir-lhe estabelecer quais os próximos passos a serem dados, bem como ajudar a delinear como poderiam ser. A maturidade é um importante elemento de auxílio para o planejamento estratégico de qualquer organização, inclusive para aglomerados produtivos (PIETROBON, 2009, p. 17).
}

A identificação do nível de maturidade de um aglomerado pode responder à questões que auxiliam o aglomerado a seguir amadurecendo, conhecer sua atual 
situação e como evoluir. E ainda pode auxiliar em apontar pontos fortes e fracos, apoiando o planejamento estratégico do mesmo, completa Pietrobon (2009).

É natural tamanha significância da maturidade para os aglomerados produtivos, uma vez que são sistemas que possuem foco voltado principalmente para produtividade, já que diversos exemplos da prática têm mostrado que a produtividade é alavancada por meio da maturidade.

Porém a produtividade não é o único foco dos arranjos. Os que vêm se mostrando maduros, apresentam maior flexibilidade para lidar com questões bem mais amplas, que por fim se desdobram em capacidade produtiva e benefícios mútuos. Isso inclui preocupação com a qualidade de vida e qualidade de vida no trabalho dos colaboradores; capacidade de se beneficiar de forma eficaz com o incentivo das instituições de pesquisa e desenvolvimento aliadas ao arranjo; investimento em inovação; responsabilidade socioambiental, além de vários outros aspectos.

Porém, atingir alto nível de desenvolvimento/maturidade exige um planejamento detalhado e uma sinergia de esforços. Normalmente quem desempenhada este papel de direcionar os passos a serem seguidos na busca pelo desenvolvimento é a governança do aglomerado. Assim, para que esta tarefa seja realizada com maior eficiência, se faz necessário o conhecimento do nível de maturidade que o aglomerado se encontra e quais as lacunas a serem supridas.

Neste contexto, aplica-se a ideia de que a governança corporativa dos aglomerados produtivos é que está diretamente ligada à maturidade do mesmo. A literatura mostra que quanto maior a condição de interação entre governança e os membros associados, bem como a coerência das decisões tomadas peça liderança, maior o potencial para amadurecimento do aglomerado como um todo.

Suzigan et al. (2007) dizem que:

[...] por governança em arranjos ou sistemas produtivos locais entende-se a capacidade de comando ou coordenação que certos agentes (empresas, instituições, ou mesmo um agente coordenador) exercem sobre as interrelações produtivas, comerciais, tecnológicas e outras, influenciando decisivamente o desenvolvimento do sistema ou arranjo local (SUZIGAN et. al, 2007, p. 1).

Se a governança interferir de forma positiva e eficiente nos aspectos citados por este autor, a tendência é o aglomerado ter atingido um perfil maduro ou estar a 
caminho deste.

Pietrobon (2009) ainda argumenta que analisar o nível de maturidade possui um objetivo mais intrínseco que a própria análise, e que este objetivo mais interno é o de saber onde se está, qual a idealização de formato que se desejaria estar e como chegar a este nível. Para o autor "unindo-se estes três momentos: onde se está (situação atual), aonde se quer chegar (situação futura desejada) e como chegar lá (planos de ação), fica evidente a importância do estabelecimento de níveis de maturidade".

Para Porter (2004) uma vez adotada uma postura de busca por maturidade, ou já tendo sido atingido certo nível desta, o momento é de mudança no enfoque competitivo, onde obviamente existem alterações na estrutura e nos sistemas organizacionais, sendo indispensáveis estruturas projetadas para ressaltar e controlar áreas diferentes do negócio.

O autor sugere "um orçamento mais apertado, um controle mais rígido e novos sistemas de incentivos baseados no desempenho", como fatores que também podem ser necessários na maturidade. Afirma ainda ser necessário que neste momento uma maior importância seja dada ao controle de ativos financeiros, como estoque e contas a receber e afirma que todos estes tipos de mudanças são básicos para reversões bem sucedidas.

Assim, fica clara a significância das estruturas de governança para a maturidade do sistema, uma vez que a implementação das medidas organizacionais de sistemas maduros sugeridas por Porter é uma atribuição da governança.

Desta forma, esse trabalho tem como escopo a aplicação da metodologia de análise de maturidade, apresentada por Pietrobon (2009), no aglomerado de bonés da cidade de Apucarana - PR, visando identificar seus pontos fortes e fracos, assim como conhecer sua situação atual e indicar estratégias para sua evolução.

\section{METODOLOGIA APLICADA}

A presente pesquisa classifica-se como uma pesquisa de natureza aplicada, pois visa gerar conhecimentos para aplicações práticas úteis para a solução de problemas específicos, neste caso, a pouca abordagem na literatura acerca da maturidade em aglomerados produtivos, em contraste com a importância deste 
conceito na prática das organizações produtivas. Também se classifica como sendo uma pesquisa quali-quantitativa. Ainda, sob a ótica de seus objetivos a pesquisa é classificada como exploratória.

Este estudo diagnosticou e analisou o nível de maturidade do Arranjo Produtivo Local de Bonés de Apucarana, sendo isto feito por meio da aplicação do instrumento especialista desenvolvido por Pietrobon (2009), onde este foi aplicado ao gestor (coordenador) do arranjo.

O instrumento possui 40 questões de múltipla escolha contendo quatro alternativas para cada questão, as quais visam avaliar, da forma mais fidedigna possível, a maturidade do aglomerado estudado.

As questões do instrumento estão dividas em 14 dimensões-chave, estabelecidas pelo autor como sendo as dimensões constituintes da maturidade para um APL. Essas dimensões são consideradas situações envoltas às ações cotidianas e de desenvolvimento, ou ainda, variáveis relacionadas à gestão e melhoria contínua dos aglomerados produtivos.

Essas dimensões se fazem com uma certa abrangência e complexidade. Por este motivo, elas são exploradas através de quatro ou cinto perguntas, conforme a dimensão. Assim, objetiva-se cercar o maior número de possibilidades de resposta para os questionamentos presentes em uma dada dimensão.

Entretanto, mapear diversos aspectos dessas organizações produtivas é uma tarefa difícil, pois de acordo com (Suzigan, 2005), os aglomerados são organismos com variações muito específicas, possuindo uma série características e defeitos próprios. Ainda assim, o instrumento utilizado nesta pesquisa tem-se mostrado eficiente e atualizado para o tipo de avaliação que propõe.

As perguntas de cada dimensão ainda são subdivididas em quatro alternativas de múltipla escolha, de forma que a primeira (letra "a") sempre possui um valor de 10 pontos, a segunda (letra "b") um valor de 6 pontos, a terceira (letra "c") valendo 2 pontos e a última opção (letra "d") não valendo pontos da qual representa ausência de maturidade no aspecto avaliado por meio daquela questão. De forma análoga, atingir 10 pontos em uma das perguntas significa um elevado nível de maturidade para o aspecto que está sendo avaliado.

Pietrobon (2009) propõe ainda um coeficiente de maturidade construído em função dos pontos obtidos no questionário. O somatório dos pontos obtidos no 
instrumento pode atingir no máximo um valor de 400 pontos, e o coeficiente pode variar, em função da pontuação, de 1 a 5, representando uma condição nula de maturidade (fato que não caracteriza arranjos produtivos locais) e uma condição ótima de maturidade, respectivamente.

\subsection{Local da Pesquisa}

O município de Apucarana está localizado no Vale do Ivaí, estado do Paraná, possuindo uma população de aproximadamente 115 mil habitantes estimada pelo IBGE em 2005, sendo 57 mil desses, economicamente ativos, com um Produto ]interno Bruto PIB per capita de $\mathrm{R} \$ 8.612,99$.

As empresas fabricantes de bonés, a partir do ano de 2003 passaram a se integrar a partir da implantação do modelo de APL apoiadas por entidades locais e pelo SEBRAE-PR. No ano de 2004 formou-se o comitê gestor (governança) do APL de Bonés de Apucarana, com participação de empresários e entidades colaboradoras, responsáveis pela elaboração do plano estratégico do APL, atingindo como resultado um grupo de ações que norteariam os trabalhos em torno da inovação, qualidade e sustentabilidade do setor (REDE APL PARANÁ, 2010).

De acordo com a ACIA (2006), integram o APL de Confecção de Bonés na região de Apucarana e Ivaiporã 538 empresas. Deste grupo, o censo industrial realizado no ano de 2006, levantou 141 empresas correlatas aos itens fabricados pelas empresas do APL, atingindo uma produção de 53.266.262 peças naquele ano, sendo os bonés $83 \%$ do total e os restantes $17 \%$ outros produtos como chapéus, gorros, toucas e camisetas.

O censo industrial realizado por ACIA e IPARDES (2006) ainda classifica o porte das empresas pertencentes ao aglomerado de acordo com a produção anual de cada uma. Dessa forma, o censo constatou que $41,8 \%$ das empresas integrantes do APL são microempresas, $28,4 \%$ são pequenas empresas e $7,1 \%$ grandes empresas.

Em termos de produção, as 53.266.262 peças produzidas em 2006 representam apenas $72,92 \%$ da capacidade produtiva do aglomerado naquele ano. Essa diferença revela uma ociosidade de $27,08 \%$ dos fatores de produção. Isso pode ser um indício de imaturidade do sistema produtivo em algum aspecto, fato que 
pode ser verificado por meio da avaliação do nível de maturidade do mesmo, de forma a especificar qual é a dimensão do aglomerado que necessita de melhorias para suprir esta lacuna de produção, isto é, se investimentos devem ser feitos em mapeamento e padronização de processos, treinamentos específicos de mão de obra ou em outros pontos.

A Rede APL Paraná (2010) afirma existir em Apucarana mais de 400 empresas do setor e que $60 \%$ dos bonés produzidos no Brasil são provenientes deste aglomerado. São bonés promocionais, de grifes, de magazine, profissionais e de marca própria. O domínio de mercado no setor mostra a grande flexibilidade do arranjo, dada a crescente concorrência nacional e até mesmo externa. O mesmo autor ainda considera que a qualidade e competividade presentes no setor de bonés são frutos da implementação do sistema produtivo local. Com estes atributos a cidade é reconhecida como capital nacional do boné.

\section{RESULTADOS E DISCUSSÕES}

Após a aplicação do instrumento para o gestor do Arranjo Produtivo Local de Apucarana, os dados coletados foram analisados separadamente para cada uma das 14 dimensões que está subdivido. Os resultados a seguir consistem em verificar qual a pontuação obtida para cada dimensão, em relação aos pesos atribuídos a cada alternativa de cada questão. As ponderações feitas para cada dimensão são diretamente baseadas no questionário resultante da metodologia de análise de maturidade desenvolvido por Pietrobon (2009) aplicada ao APL de Bonés de Apucarana.

Dimensão 1: Aceitação do assunto. Em relação à aceitação do assunto (aglomerado produtivo) em torno de seu escopo de entendimento por parte da alta administração do aglomerado (chefias superiores que possuem alguma influência sob o aglomerado produtivo), têm o assunto bastante conhecido e aceito como uma boa prática há, pelo menos, um ano. A alta administração estimula o desenvolvimento do aglomerado produtivo (10 pontos).

Por parte do setor, a aceitação do assunto, da mesma forma que para a alta administração, têm o assunto bastante conhecido, onde os gerentes - proprietários membros do aglomerado produtivo se sentem estimulados a utilizar esses 
conhecimentos (10 pontos). Já por parte dos clientes o assunto é razoavelmente conhecido e aceito como uma boa prática por uma parcela dos clientes (6 pontos).

Dimensão 2: Aspecto treinamento. Se tratando de nível de conhecimento técnico dos assuntos em relação a aglomerados e/ou sobre a área do negócio atuante desse por parte de suas equipes de desenvolvimento/coordenação, constatou-se que essas equipes ainda não possuem um nível de conhecimento adequado, mas que práticas para sua evolução estão à disposição, e sendo utilizados (6 pontos).

No que tange a treinamentos internos ao aglomerado produtivo, este dá suma importância a este aspecto e freqüentemente promove cursos internos, os quais abordam assuntos técnico-administrativos e de escopo metodológicos (10 pontos). Já em relação aos treinamentos feitos externamente ao aglomerado produtivo, e que foram realizados nos últimos doze meses (cursos de aperfeiçoamento, graduação, seqüenciais, MBA, mestrado, certificação, entre outros), para os profissionais atuantes do setor e que possuam envolvimento com o gerenciamento, o aglomerado de bonés aceita tais iniciativas, mas não prevê nenhuma vantagem de carreira para os participantes (2 pontos).

Dimensão 3: Treinamento gerencial. Primeiramente analisou-se o tipo de abrangência do treinamento fornecido aos gerentes das empresas no aglomerado, onde essa atingiu uma quantidade insuficiente dos gerentes (6 pontos). Já no que se trata do tipo de abrangência do treinamento fornecido para alta administração, esse teve uma deficiência em relação ao número de áreas de gerenciamento em relação àquelas destacadas como necessárias à alta administração do setor (2 pontos).

Indagou-se também sobre qual o entendimento da importância de aspectos organizacionais para o bom andamento das atividades do aglomerado, onde se verificou que as principais lideranças do setor e da alta administração da organização conhecem o assunto (aglomerado produtivo), têm absorvida sua importância para o sucesso do setor de bonés e dão apoio para sua implantação e aperfeiçoamento (10 pontos).

Além desses, buscou-se saber ainda, quanto ao treinamento em aglomerado produtivo para o gerenciamento de atividades conjuntas como seqüenciamento de tarefas, cronogramas, etc. Nesse quesito, o APL de Apucarana desenvolve atividades, mas apenas algumas pessoas as conhecem por meio de iniciativa 
pessoal (2 pontos).

Dimensão 4: Mapeamento e padronização de processos. Nessa dimensão constatou-se o uso de uma metodologia para o desenvolvimento do aglomerado, já implantada, testada e em uso rotineiro por todos os principais envolvidos diretos com o aglomerado ao menos há um ano (10 pontos). Ainda sobre essa metodologia, constatou-se que o nível de informatização desta está consolidada, adequada aos tipos de atividades do setor, e disponível e em uso para todos os membros do aglomerado também ao menos há um ano (10 pontos).

Em relação direta ao mapeamento e padronização de processos, mais precisamente os que envolvem as etapas para criação dos produtos do aglomerado produtivo, o que engloba fatores como a criação e o surgimento de ideias, o estudo da viabilidade e suas aprovações em relação ao planejamento estratégico do aglomerado e/ou produtos desse, viu-se que apenas alguns processos foram até então mapeados, padronizados e, alguns, informatizados a mais de um ano no APL (6 pontos).

Dentro do aspecto planejamento, surge o planejamento de cada nova atividade do aglomerado produtivo e posteriormente a confecção do plano de execução dessas atividades, onde no aglomerado de bonés esse processo é feito conforme padrões estabelecidos que demandem diversas reuniões entre os principais envolvidos. O modelo estabelece diferenciações entre atividades pequenas, médias e grandes e é bem aceito pela organização há mais de um ano (10 pontos).

Dimensão 5: Estrutura organizacional. Avaliou-se nessa dimensão a estrutura organizacional implantada no aglomerado produtivo. Constatou-se que essa foi construída a partir de uma avaliação do tipo de estrutura organizacional mais adequada e possível no momento, e por um acordo comum de uma estrutura contendo todos os membros do aglomerado produtivo, e ainda, que essa estrutura já está em funcionamento há mais de um ano (10 pontos).

Em seguida foi diagnosticado que a coordenação do aglomerado produtivo, em relação à estrutura organizacional existente, foi implantada e está operando há mais de um ano (10 pontos). Ainda no aspecto de coordenação, verificou-se a existência de comitês para o acompanhamento das atividades do aglomerado, implantados e operando há mais de um ano. Esses comitês reúnem-se 
periodicamente e têm forte influência no andamento das atividades do aglomerado produtivo (10 pontos).

Outro aspecto abordado foi a ocorrência de reuniões de avaliação do andamento das atividades do aglomerado produtivo, entre a coordenação, os comitês, os membros e outros agentes envolvidos. Obteve-se a resposta de que essas reuniões são organizadas segundo uma disciplina preestabelecida que prevê horário, local, pauta, participantes, relatórios, etc. As reuniões permitem que todos os membros percebam o andamento do aglomerado produtivo (10 pontos).

Avaliou-se também o acompanhamento da execução de cada atividade do aglomerado produtivo. Contatou-se que os dados adequados são coletados periodicamente, e é feita uma comparação com o previsto. No caso de desvio da meta, contra medidas são identificadas, designadas aos responsáveis e acompanhadas. Esse modelo está em funcionamento eficientemente há mais de um ano. Mas, além disso, no APL de Apucarana as contramedidas nem sempre surtem o efeito esperado ( 6 pontos).

Dimensão 6: Planejamento estratégico. Analisou-se inicialmente o planejamento de forma técnica agregado ao produto que está sendo desenvolvido de forma conjunta no aglomerado. Constatou-se que esse é de muito boa qualidade e o aglomerado tem utilizado com muita propriedade a mais de um ano (10 pontos).

Já em termos históricos de atividades já executadas em conjunto no aglomerado, no que tange aspectos como qualidade do produto/serviço que foi criado, reversão de investimento, qualidade do gerenciamento e armazenamento de lições aprendidas, foi criado um banco de dados para a coleta desses dados e já existe uma razoável quantidade desse tipo de informações estando em uso há mais de dois anos, auxiliando assim para o planejamento de novas atividades de desenvolvimento no aglomerado e evitar erros cometidos anteriormente (10 pontos).

Em relação à gestão de portfólio e de programas identificados no Planejamento Estratégico para o aglomerado produtivo, no diagnóstico do aglomerado de bonés deu-se que os portfólios e programas não possuem um gerente próprio. Os diversos membros do aglomerado produtivo relacionados com os portfólios e programas procuram manter alguma sincronia com o responsável pelas metas estratégicas da organização através do coordenador do aglomerado (6 pontos) 
Dimensão 7: Melhoria contínua. Primeiramente deu-se enfoque à melhoria contínua no modelo de gerenciamento do aglomerado praticada por meio de controle e medição da metodologia e do sistema informatizado. Nesse aspecto o modelo implantado é permanentemente avaliado através do controle e medição do uso. Os aspectos que mostram fragilidade ou inadequabilidade são discutidos e aperfeiçoados. Esse modelo tem evoluído de forma a satisfazer os principais envolvidos (10 pontos).

Outro aspecto analisado são as anomalias em tarefas que estão em andamento ou que acabaram de ser executadas. Anomalias como inicio das tarefas muito fora do previsto, estouro de orçamento, duração muito além da prevista, etc. Nesse sentido, no aglomerado pesquisado existe um sistema de coleta de informações no qual se apontam as causas das anomalias e, posteriormente, é efetuada uma análise para identificar os principais fatores ofensores que se repetem (Análise de Pareto), que foi recentemente implantado e está se criando uma cultura para seu uso (6 pontos).

Já em relação às causas de fracasso de atividades já encerradas como atrasos, não obediência ao escopo previsto, estouro de orçamento, não atendimento às exigências de qualidade, as quais são oriundas do próprio aglomerado produtivo ou de fatores externos, constatou-se que todas as principais causas de fracasso foram identificadas. Foram estabelecidas e implantadas contra as medidas para evitar que estas causas se repitam. Este trabalho vem sendo realizado com sucesso a mais de dois anos (10 pontos).

Dimensão 8: Relacionamento. Em relação à estrutura organizacional existente, é possível afirmar que a estrutura implantada anteriormente para governar o relacionamento entre os membros e o aglomerado evoluiu, há mais de dois anos para uma estrutura realmente correta e necessária, tendo em vista as exigências dos relacionamentos. Os membros do aglomerado possuem e exercem a autoridade necessária e adequada junto à governança deste (10 pontos).

Dimensão 9: Governança. Em termos de governança exercida pelo coordenador do aglomerado produtivo, identificou-se qual o nível de estímulo para este no sentido de atingir as metas da proposta pelo conjunto de empresas e da transparência das atividades realizadas. Identificou-se a existência de um sistema de avaliação específico ao coordenador do aglomerado, mas esse foi recentemente 
implantado, há menos de um ano (6 pontos).

Dimensão 10: Liderança. Nessa questão, foram analisados os quesitos em relação ao aperfeiçoamento da capacidade dos membros do aglomerado produtivo, com ênfase em relacionamentos humanos como liderança, conflitos, negociação e motivação. No aglomerado de Apucarana tem havido algumas iniciativas de treinamento por parte da aglomeração produtivo, mas estas se encontram em estágio inicial (2 pontos).

Dimensão 11: Certificação. Em relação ao estímulo para a obtenção de certificação pelos membros do aglomerado produtivo de bonés, existe um plano de execução para estimular esses membros a obter uma certificação ISO ou equivalente. Similar a isso, quanto aos profissionais, existe também um plano de implantação de atividades de certificação de desempenho profissional e/ou o 5 S. Todavia, apenas uma pequena fração dos gerentes-membros do aglomerado produtivo deverá obter certificação ou desenvolver atividades neste sentido (6 pontos).

Ainda dentro do escopo de certificação e/ou padronização, pesquisou-se sobre o alinhamento das atividades executadas no aglomerado com os negócios dos membros constituintes deste ou com o planejamento estratégico do aglomerado. Constatou-se que não existem critérios para que as novas atividades sejam implantadas somente se estejam alinhadas com os negócios dos membros do aglomerado produtivo, sendo isso feito ao acaso (0 pontos).

Dimensão 12: Parcerias. Inicialmente para essa dimensão, constatou-se a existência de um histórico de atividades já executadas em conjunto no aglomerado, no que toca aspectos de casos aplicáveis como retorno de investimento, qualidade do gerenciamento, qualidade técnica e desempenho do produto obtido e comercializado. Nesse ponto viu-se que existe um banco de dados ou algo relacionado, que não pode ser classificado de amplo e excelente ou não é utilizado rotineiramente pelos membros do aglomerado produtivo (0 pontos).

Já em relação às lições aprendidas, o aglomerado produtivo de bonés tem um amplo e excelente banco de dados, que é utilizado rotineiramente pelos membros deste há, pelo menos, dois anos (10 pontos).

Mantendo-se ainda na dimensão "parcerias", verificou-se quanto à avaliação da estrutura organizacional implantada no aglomerado em relação a comitês, 
governança, parceria com a Rede Aglomerado Produtivo do Paraná. Percebeu-se que a estrutura implantada é perfeitamente adequada ao setor, e funciona de forma totalmente convincente há pelo menos dois anos (10 pontos).

Por fim, verificou-se a visibilidade da organização deste aglomerado produtivo na comunidade empresarial e em outros aglomerados, tendo como resposta pelo coordenador do APL de Apucarana a opção do questionário que coloca a resposta da seguinte forma: Nossa organização é vista e citada como benchmark em gerenciamento de projetos há, pelo menos, 2 anos. Recebemos freqüentes visitas de outras organizações para conhecer nosso sistema de gerenciamento de projetos (10 pontos).

Dimensão 13: Clima organizacional. Primeiramente indagou-se sobre a capacidade dos membros do aglomerado produtivo em relacionamentos humanos como negociação, motivação, conflitos, etc. Constatou-se que quase a totalidade dos membros do aglomerado é altamente avançada nesses aspectos há pelo menos dois anos (10 pontos).

Logo após verificaram-se informações correlatas ao clima existente entre os membros do aglomerado, onde se constatou que o assunto é visto com receio por alguns dos membros. O planejamento das atividades é razoável e verifica-se de boa eficiência com um bom clima de trabalho e envolvimento (6 pontos).

Outro aspecto que interfere no clima organizacional são os fracassos das atividades do aglomerado produtivo como, por exemplo, estouro de orçamento, atrasos, não obediência ao escopo previsto, não atendimento a exigências de qualidade, desunião. Para tal identificou-se o conhecimento sobre as causas que resultam nos fracassos tanto internos quanto externos ao aglomerado produtivo, onde essas são pouco trabalhadas e analisadas (2 pontos).

Dimensão 14: Tecnologia da informação. Em relação à informatização do aglomerado produtivo, essa, segundo seu coordenador, é boa, mas deixa vários aspectos a serem melhorados (2 pontos).

Por fim indagou-se em relação ao alinhamento do aglomerado produtivo com os negócios dos membros ou com o planejamento estratégico do aglomerado, tendo como resposta que o alinhamento é de $50 \%$, em média (2 pontos). 


\subsection{Nível de maturidade do APL de bonés de Apucarana}

Aplicando o resultado da pesquisa, pode-se obter o coeficiente de maturidade do Arranjo Produtivo Local de Bonés de Apucarana, totalizando 3,74, que o enquadra aos padrões qualitativos dos cinco níveis de maturidade pontuados por Pietrobon (2009), e descritos no quadro 1.

Quadro 1 - Coeficiente de maturidade

\begin{tabular}{|c|c|c|c|c|}
\hline$-1-$ & $-2-$ & $-3-$ & $-4-$ & $-5-$ \\
INICIAL & CONHECIDO & PADRONIZADO & GERENCIADO & OTIMIZADO \\
\hline $\begin{array}{c}\text { Boa vontade } \\
\text { (entre 1 e 2) } \\
\text { ou } \\
\text { maturidade nula } \\
\text { (igual a 1) }\end{array}$ & $\begin{array}{c}\text { Linguagem } \\
\text { Comum }\end{array}$ & Praticado & Consolidado & Sabedoria \\
\hline
\end{tabular}

Fonte: Pietrobon (2009)

De acordo com esse padrão de avaliação, a maturidade do APL de bonés de Apucarana está nesse momento entre os níveis 3 e 4. Pietrobon (2009) afirma que um aglomerado que possui em seu diagnóstico de maturidade um valor igual a ou maior a isso, se encontra em um nível padronizado.

Assim, "neste momento da maturidade o aglomerado apresenta um cenário onde está implantado e se utiliza um modelo padronizado de gerenciamento. Há liderança e governança firmadas que desenvolvem a integração entre os membros. Há uma base metodológica de trabalho e atividades conjuntas ocorrendo com freqüência e de forma harmoniosa e cooperativa entre os membros. É nesta fase que ocorrerá a ruptura que elevará o aglomerado a um patamar diferenciado em termos de maturidade (levando-o a ascender a níveis superiores de maturidade)" (PIETROBON, 2009, p.61).

Já o nível gerenciado (pontuação igual a 4), que é o outro limite superior do intervalo do desenvolvimento da maturidade que se encontra o APL de Apucarana “ [...] é o momento que existirão ações como o alinhamento das atividades com as estratégias das empresas membro, ou seja, as ações realizadas dentro do aglomerado produtivo serão parte integrante das estratégias de cada membro do aglomerado; e ocorrerão relacionamentos humanos eficientes, existirá um relacionamento humano sadio e austero entre os membros, abordando, principalmente o gerenciamento de pessoas e negociações (no estilo ganha - 
ganha)." (PIETROBON, 2009, p. 61).

Assim, tendo em vista que o molde de atuação industrial em aglomeração produtiva no setor de bonés de Apucarana é recente, trabalhos estão sendo feitos com o objetivo de aumentar a capacidade do grupo de empresas constituintes do aglomerado (em termos quantitativos e qualitativos), verificando-se assim que este aglomerado se encontra em um momento de progresso em relação à sua taxa de desenvolvimento, o que fomenta a oportunidade neste momento de ações voltadas à evolução (melhoria) do modelo de gestão existente a partir de medidas partidas da governança.

Devido ao escore obtido, o APL de Apucarana se encontra mais próximo da dimensão gerenciado do que apenas padronizado. Entretanto, dentre as linhagens que tem defasado a maturidade do sistema, está o treinamento técnico e gerencial. Assim, observa-se que, exceto os profissionais qualificados que pertencem às instituições das chamadas "economias externas locais", o aglomerado não tem direcionado esforços com o objetivo de formação gerencial para atuar especificamente dentro da governança e liderança de forma a visualizar o planejamento estratégico adequado à realidade do aglomerado, fato que pode ser auxiliado a partir da presente avaliação.

\section{CONSIDERAÇÕES FINAIS}

A organização das MPE de confecção de bonés do município de Apucarana em Arranjo Produtivo Local demonstra o quanto os empresários souberam absorver e potencializar os benefícios que as ações conjuntas trazem ao setor, através da inovação por meio da difusão do conhecimento tácito e qualificação da mão de obra.

A pesquisa feita no aglomerado produtivo de bonés de Apucarana leva à percepção da organização, a responsabilidade em relação às atividades referentes ao desenvolvimento do aglomerado. Entretanto, ainda existem algumas vertentes que requerem um maior investimento por parte da governança, que se planejadas e executadas com êxito podem elevar a potencialidade do aglomerado produtivo local para um sistema produtivo e inovativo local, que segundo Pagani (2006), Betim (2007) e Cassiolato e Lastres (2003) são sistemas onde há uma maior interação, elos mais firmados entre as unidades. 
O foco desses sistemas não são somente seus atores, mas também, todos os aspectos que agregam valor às capacidades das empresas constituintes do aglomerado. Fatores estes que habitualmente incrementam a eficiência coletiva pela ótica da inovação. Isto é, são altamente maduros, certamente com coeficientes próximos de 5 , segundo este tipo de avaliação.

Contrastando as medidas que vem sendo tomadas para o desenvolvimento do APL apresentadas pela literatura (sobretudo o plano de desenvolvimento do aglomerado) com os resultados obtidos, conclui-se também que é necessário ter uma equipe de colaboradores competentes, preço justo, qualidade do produto e prontidão no atendimento para alcançar um elevado grau de eficiência nesse sistema produtivo.

Assim, coaduna-se que se medidas como essas (potencializar os aglomerados pelo viés da maturidade) forem tomadas em massa, isto é, forem acatadas pelos vários sistemas de produção distribuídos ao longo do território nacional, as vantagens econômicas não vão atingir apenas o âmbito local e regional, mas em uma esfera nacional, a partir de uma melhor distribuirão de renda, de uma economia mais fortalecida perante a concorrência externa e as crises de mercado com certa freqüência abalam a economia mundial. Essas vantagens competitivas são alcançadas com maior facilidade por sistemas maduros.

Assim espera-se que a consciência da significância econômica dos aglomerados produtivo esteja presente em toda sociedade local e regional, sobretudo que isto seja bastante claro nas estruturas de governança desses sistemas, de forma a constantemente avaliarem o desempenho do aglomerado, elaborem medidas que propulsionem desenvolvimento e que não sejam os planos voltados unicamente para os lucros empresariais, mas também a consciência de promoção de uma maior homogeneidade de distribuição de renda local, promoção da qualidade de vida dos trabalhadores, responsabilidade ambiental, formação de parcerias efetivas com instituições de pesquisa e desenvolvimento (P\&D), investimento em inovação e outras atitudes. Acredita-se que todos estes fatores, por fim se desdobram nas vantagens competitivas. 


\section{REFERÊNCIAS}

ALBAGLI, S. \& BRITO, J. (Orgs.). Glossário de arranjos e sistemas produtivos e inovativos locais. projeto arranjos produtivos locais: uma nova estratégia de ação para o SEBRAE. Redesist, fev. 2003.

ALTER, C. \& HAGE, J. Organizations working together. California: SAGE, 1993.

AMATO NETO, J. Redes de cooperação produtiva e clusters regionais: oportunidades para pequenas e médias empresa. São Paulo: Atlas, 2000.

ACIA - ASSOCIAÇÃO COMERCIAL, INDUSTRIAL E DE SERVIÇOS DE APUCARANA; et. al. Censo Industrial do arranjo produtivo local de confecções de bonés de Apucarana no estado do Paraná. Curitiba: IPARDES, 2006.

BETIM, L.M. Caracterização da estrutura organizacional do aglomerado produtivo de Telêmaco Borba - PR. 150 p. Dissertação (Mestrado em Engenharia de Produção). PPGEP-UTFPR. Ponta Grossa, 2007.

CAMARA, M. R. G. \& OLIVEIRA, M. A. \& SOUZA, L. G. A. O corredor da moda do Norte - Noroeste do Paraná à luz dos arranjos produtivos locais. Revista

Paranaense de Desenvolvimento, Curitiba: IPARDES, n. 110, jan./jun. 2006.

CASSIOLATO, J. E. \& LASTRES, H. M. \& MACIEL, M. L. (orgs.) O foco em arranjos produtivos e inovativos locais de micro e pequenas empresas. In: "Pequena empresa: cooperação e desenvolvimento local". Rio de Janeiro: Relume Dumará, 2003.

ERBER, F. S. Eficiência coletiva em arranjos produtivos locais industriais: comentando o conceito. Revista nova economia, v.18, n.1, pp. 11-31, 2008.

GARNICA, J. R. V \& CONTRERAS, F. A. G. Los cluster industriales: precisión conceptual y desarollo teórico. Cuad. Adm. Bogotá-Colômbia, v.20, n.33, jun. 2007.

GIL, A.C. Como elaborar projetos de pesquisa. 4. ed. São Paulo: Ed. Atlas, 2002.

IPARDES - INSTITUTO PARANAENSE DE DESENVOLVIMENTO ECONÔMICO ECONOMICO E SOCIAL. Arranjo Produtivo Local de Bonés de Apucarana. Nota Técnica. Curitiba: IPARDES, 2006.

PAGANI, R.N. Análise da aglomeração produtiva do setor de móveis de metal e sistemas de armazenagem e logística de Ponta Grossa - PR. 146 p. Dissertação (Mestrado em engenharia de Produção). PPGEP-UTFPR. Ponta Grossa, 2006.

PIETROBON, F. Proposta de um modelo para identificação do nível de maturidade de aglomerados produtivos. $117 \mathrm{p}$. Dissertação (Mestrado em Engenharia de Produção). PPGEP-UTFPR. Ponta Grossa, 2009. 
PORTER, M.E. Clusters e Competitividade. HSM Management. n. 15, ano 3, julho/agosto de 1999.

PORTER, M.E. Competição: estratégias competitivas essenciais. 16. ed. Rio de Janeiro: Campus, 1999.

PORTER, M.E. Estratégia competitiva: técnicas para análise de indústrias e da concorrência. 2. ed. Rio de Janeiro: Elsevier, 2004.

PRADO, D.S. Gerenciamento de portfólios, programas e projetos nas organizações. Nova Lima-MG: IDNG, 2004.

REDE APL PARANÁ. Perfil do arranjo produtivo local de bonés de Apucarana PR. Disponível em: < http://www.redeapl.pr.gov.br>. Acesso em: 12 abr. 2010.

REDESIST. Glossário de arranjos produtivos e sistemas inovativos e produtivos locais. 5. rev. Jun. 2005.

SEBRAE; et al. Plano de desenvolvimento do arranjo produtivo local de bonés de Apucarana - Paraná, 2005.

SUZIGAN, W.; GARCIA, R. \& FURTADO, J. Estruturas de governança em arranjos ou sistemas locais de produção. Revista Gestão \& Produção. São Carlos, v.14, n.2, p. 425-439, 2007.

SUZIGAN, W. \& GARCIA, R. \& FURTADO, J. Sistemas locais de produção/inovação: metodologia para identificação, estudos de casos e sugestões políticas. In: DINIZ, C. C. \& LEMOS, M. B. (orgs.) Economia e território. Belo Horizonte: Editora UFMG, 2005. Cap. 9, p. 287-338.

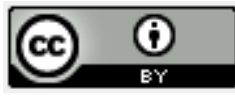

Artigo recebido em 23/11/2010 e aceito para publicação em 17/08/2011. 